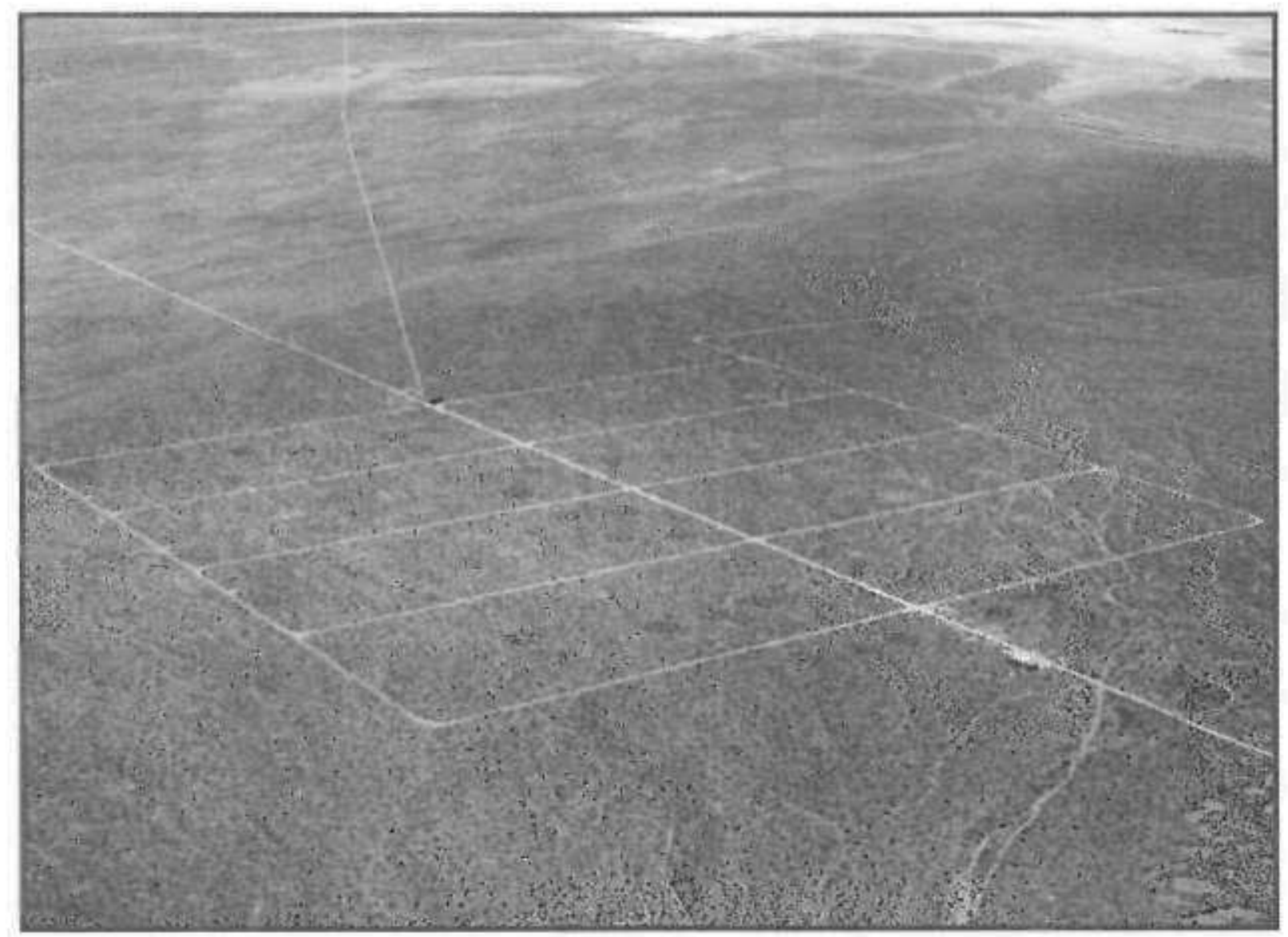

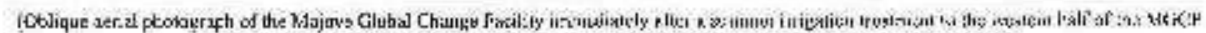

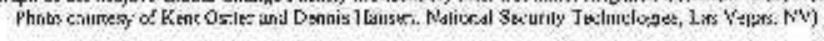

\title{
Effects of Changing Water and Nitrogen Inputs on a Mojave Desert Ecosystem
}

\author{
DOEH DE-FG03-02ER6336।
}

\section{Prepared By}

Stanley D. Smith, University of Ncrada Las Vegas

Robert S. Nowak, University of Nevada Reno

Lynn F, Fenstermaker, Desert Research Institute

Michad H. Young, Desert Research Institute

November 30,2007 


\title{
Effects of Changing Water and Nitrogen Inputs on a Mojave Desert Ecosystem
}

DOE\# DF-FG03-02ER63361

\author{
Stanley D. Smith, University of Nevada, Las Vegas \\ Robert S. Nowak, University of Nevada, Reno \\ Lynn F. Fenstermaker, Desert Research Institute \\ Michael H. Young, Desert Research Institute \\ Principal Investigators \\ Final Technical Report \\ November 30,2007
}

Questions addressed under this grant shared the common hypothesis that plant and ecosystem performance will positivety respond to the augmentation of the most limiting resources to plant growth in the Mojave Desert, e.g., water and nitrogen. Specific hypotheses include (1) increased summer rainfall will significantly increase plant production through an alleviation of moisture stress in the dry summer months, (2) $\mathrm{N}$-deposition will increase plant production in this $\mathrm{N}$ limited system, particularly in wet years or in concert with added summer rain, and (3) biological crust disturbance will gradually decrease bio-available $N$, with concomitant longutern reductions in photosynthesis and ANPP. Individual plant and ecosystem responses to global change may be regulated by biogeochemical processes and natural weather variability, and changes in plant and ecosystem processes may occur rapidly, may occur only alter a time lag, or may not occur at all. During the first. PER grant period, we observed changes in plant and ecosystem processes that would fall under each of these time-response intervals: plant and ecosystem processes responded rapidly to added summer rain, whereas most processes responded slowly or in a lag fashion to $\mathrm{N}$ deposition and with no significant response to crust disturbance. Therefore, the primary abjectives of this rencwal grant were to: (1) continue ongoing measurements of soil and plant parameters that assess primary treatment responses; (2) address the potential heterogeneity of soil propertics and (3) initiate a new suite of measurements that will provide data necessary for scaling/modeling of whole-plot to ecosystem-level responses. Our experimental approach included soil plant-water interactions using TDR, neutron probe, and miniaturized soil matric potential and moisture sensors, plant ecoplysiological and productivity responses to water and nitrogen treatinents and remote sensing methodologies deployed on a radio control platform.

We report here the most significant findings of our 4 year study. 


\section{ABOVEGROUND PERENNIAL PLANT PRODLCTION [S. Smith, PT]}

Plant growth measurements [B. Newingham]

We examined the growth responses of three perennial species at the MGCF in the following treatments: control, monsoon, $10 \mathrm{~N}, 40 \mathrm{~N}$, monsoon $+10 \mathrm{~N}$, monsoon $+40 \mathrm{~N}$, and disturbance. The plant species included Lyciton pallidum, Pleuraphis rigida, and Larrea tridentata. Several growith parameters were collected for each species to represent plant production; all measurements were taken on growing tips of the plant except for the amount of biomass removed by rabbits (see below). Only a few parameters are presented here and figures are only shown for some growth parameters of L. tridentuta.

Growth measurements were taken in 2004, 2005 and 2006, which had ayerage, wet and average years of annual precipitation (Fig. 1). Growth neasurements on $L$, pallidism and $P$, rigida were taken bi-weekly during the growing season, and measurements were taken monthly on $L$. tridentata throughout the year. The phenology and length of the growing season for both $L$. pallidum and $P$. rigida varied depending on the amount of natural precipitation in a certain ycar; thereforc, the start and end datc of data collowtion varied among years.

\section{Hydrologic Year (Oct 1-Sept 30)}

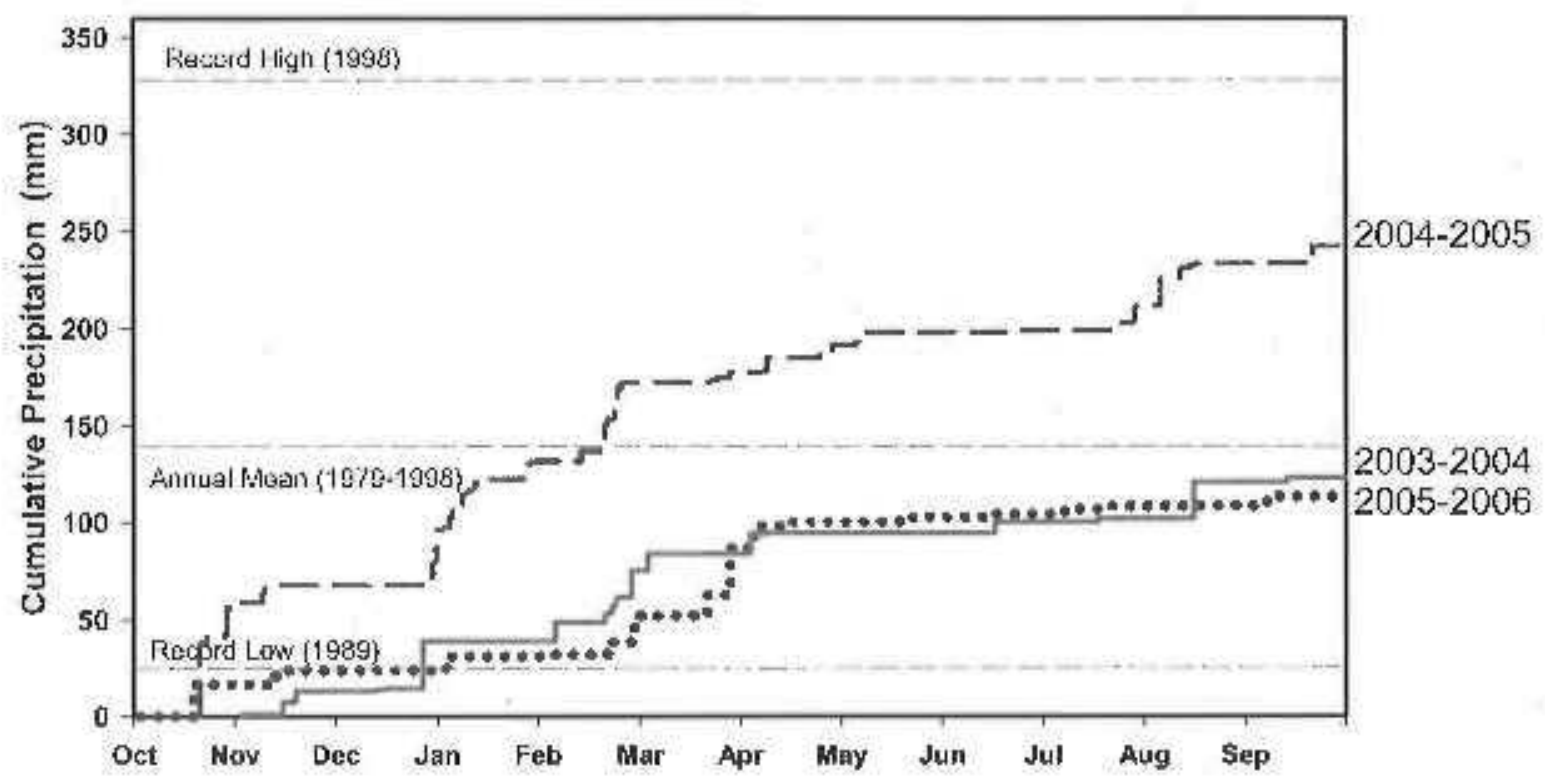

Fig.1 Precipitation over three growing seasons corresponding with data from 2004, 2005, and 2006 . Note that the hydrologic year in this area is considered to be October 110 September 30. Annual precipitition was $113.3 \mathrm{~mm}$ during $2003-2004,242.1 \mathrm{~mm}$ duting 2004-2005, and $122.9 \mathrm{~mm}$ during 2005-2006, 


\section{Results}

Lycium pallidum is a drought deciduous shrub that usually produces leaves in late April and loses its leaves in June, For L. pallidum, the number of whorls (short shoots), number of long shoots, and percent damage by insects were quantified. Regardless of treatments, $L$. pallidum growth was greatest in 2005, while very little growth occurred in 2006 . During all three yoars, $L$, puthidum did not respond to monsoon treatmenis within that same year and remained leafless after monsoon treatments. Residual effects of the previous year's watering had a negative effect on $L$. palid $d u m$ whorl production early in the season in the two average years of precipitation, but there was no effect of monsoons on long shoot production. Nitrogen deposition had no effect on whorl production; however, the number of long shoots increased in response to $\mathrm{N}$ addition in all three years.

Surprisingly, we found a positive effect of disturbance on whorl production in the wet year of 2005; however, disturbance slightly decreased long shoot production in 2004 and 2005. Plots with monsoon $+\mathrm{N}$ treatments mimicked those of the mensoon treatment, and there was no added benefit of adding $\mathrm{N}$ in those plots, Overall, growth was not affected by any treatments in 2006 . No striking palterns emerged from the herbixory data except that there are large errors associated with assessing herbivore danage, particularly in the control plots,

Plewraphis rigida is a $\mathrm{C}_{4}$ perennial grass, which is generally green mid-May to September. We determined the number of leaves, stem length, and number of llowers produced by $P$. rigida. Over all treatments, $P$. rigida growth varied among years, where substantial growth oceurred in the spring of 2004 but then drastically tapered off mid-summer. Less initial growth eccurred in 2005 and 2006 , and the growing season of 2005 was extended until late fall,

In contrast to $L$. paltidum, $P$, rigida has more potential to respond immediately to monsoon events since it is a $C_{4}$ plant and is still active in late summer. $\ln 2004, P$, rigida leaves and stem length drastically increased immediately following monsoon treatments; however, this late-season response was not seen in 2005 and 2006 . Surprisingly, monsoons had a negative efficet on stem length through the whole 2005 growing season. Nitrogen deposition had a positive effect on both leaves and stem length in 2004 but negative effects in 2005 . Disturbance negatively affected leaves and stem length early in the season in 2004 and 2005 , but these effects neutralized later in the season. Plots with monsoon + N treatments were similar to the monsom plots; however, monsoon $+\mathrm{N}$-treated plants grew $50 \%$ less in 2005. No parameters responded to treatments applied in 2006. Additionally, no treatments had strong effects on flower production.

Larrea tridentata is a $\mathrm{C}_{3}$ shrub, which is evergreen and actively grows April to September. We measured the number of leaves, branches, meristems, buds, flowers, fruits, stem length, and herbivore damage by insects and rabbits. Measurements were taken monthly from January to December in each year. We only present data on relative growth rate (RGî; based on stem length) during the active growing season (April to September) and herbivore damage by rabbits. The RGR of L. tritentata varicd among years with moderate growth in 2004, greatest growth in 2005, and negative growth in 2006 (Fig. 2).

Over the entite 2004 growing seasan, monsoon trcatments had a positive effect on the RGR of $L$. tridentata; however, $\mathrm{N}$ treatments had no effect on RGR (Fig, 2). RGR during April-May was comparable between monston and no monsoon treatments; however, plants receiving summer monsonnal rain had higher growth rates than non-irrigated plants during June through September. The lack of a nitrogen eflect on RGR was consistent throughout the season.

In 2005 there was no effect of monsoons on L. tridentata RGR for the entire growing season (Fig. 2). Most growth occurred April to July, with negative RGR during August and September for monsoon- 
treated plants. Although data suggested there was less RGR without $N$ addition, this was not statistically significant. RGR during the 2006 growing season was mostly negative, with only moderate growth in April to May in monsoon and monsoon $+10 \mathrm{~N}$ plots.

The effects of disturbanec on the RGR of $L$. tridentata depended on the growing season. Disturbance had a negative effect on RGR over the entire 2004 season, with most negative effects being seen in mid- to late summer (Fig. 3). Data from 2005 showed similar patterns as 2004 although treatment differences were not significant for any of the dates examined. Growth was almost consistently negative in control and disturbed plots in 2006 , with a surprising positive effect of disturbance on RGR in June-July.

It was observed in the late summer/early fall of 2005 that rabbits were clipping of $L$. tridentata branches. Although we did not measure rabbit population growth, it appears that the wet season of 2004-05 resulted in an increase in rabbit numbers. Of course, this damage affects our ability to estimate growth in $L$. tridentata. In Oclober 2005, we began assessing how much biomass was removed by the rabbits by collecting all clipped biomass from 4 plants per plot. In order to access the clipped branches, we had to step into the experimental plots. Therefore, biomass remowal by rabbits: was only measured in clisturbed plots. Most biomass remowal occurred in the late summer and fall of 2005 and 2006 (Fig. 4). In October and November 2005 and June and October 2006, considerable amounts of biomass were removed. During these four months, biomass removal was higher in monsoon plots than no monsoon plots. There was no effect of $\mathrm{N}$ addition on biomass removal of $L$. tridettata. The biomass removed during 2005 and 2006 partially explains the negative growth secn on $L$, fridentata growing tips, as several branches werc lost due to tabbit herbivory.

\section{Discussion}

Our results indicate that summer monsoons, nitrogen addition and disturbance can have variable effects on different plant functional groups. Underlying all of these responses is the natural precipitation received within a lydrologic year. It is important to consider not only the annual amount of precipitation but also the liming of prccipitation. Examining natural precipitation (Fig. 1) helps us interpret the growth data secn in these three perennial species.

Plant genwth responses to disturbance were intriguing. The disturbance treatment was intended to reduce $\mathrm{N}$ inputs into the ecosystem by disturbing soil microorganisms that increase plant nutrient availability. Disturbance had negative effects on the growth of $P$. rigida and $L$. tridentata in some years but not all. The negative effects of disturbance on $P$. rigida may be due to disrupting free-living $N$ fixers associated with $P$. rigida roots. Further investigation is needed to assess what causes negative growth in $P$. rigida when the soil is disturbed. At this point, we are unsure of the mechanism behind the negative effects of disturbance on $L$, tridentata.

Since the three perenuial species responded differently to these treatments, it is probable this will eventually have an effect on plant community composition; howefer, the effects on plant communities may not be immediately realized since these are such slow growing species. While the $C_{4}$ grass, $P$. rigida, and the $C_{3}$ evergreen, $L$, tridentutu, positivcly responded to monsoon treatments, the treatment likely comes too late in the season for the drought-deciduous L. pallidum to respond. However, over several years $L$, pallidum may adapt to this change and responses may be seen later on. Nitrogen addition had inconsistent effocts on plant growth with most responses by $L$, pallidum and $P$, rigida. Contrary to predictions, monsoon + nitrogen treatments did not have synergistic positive effects on plant growth. 
Changes in plant growth will not only affect plant community composition but will likely have cascading effects in the ecosystem. Increases in plant growth may cause responses by invertebrate and vertebrate herbivores, as seen in the rabbit biomass removal data. Insect sampling was also conducted in experimental plots during 2004 and 2005. Preliminary results from 2004 found that insect abundance increased immediately following monsoon treatments, but $\mathrm{N}$ addition had no effect on insect abundance. Further investigation in insect responses and linking these with changes in plant growth aro needed.
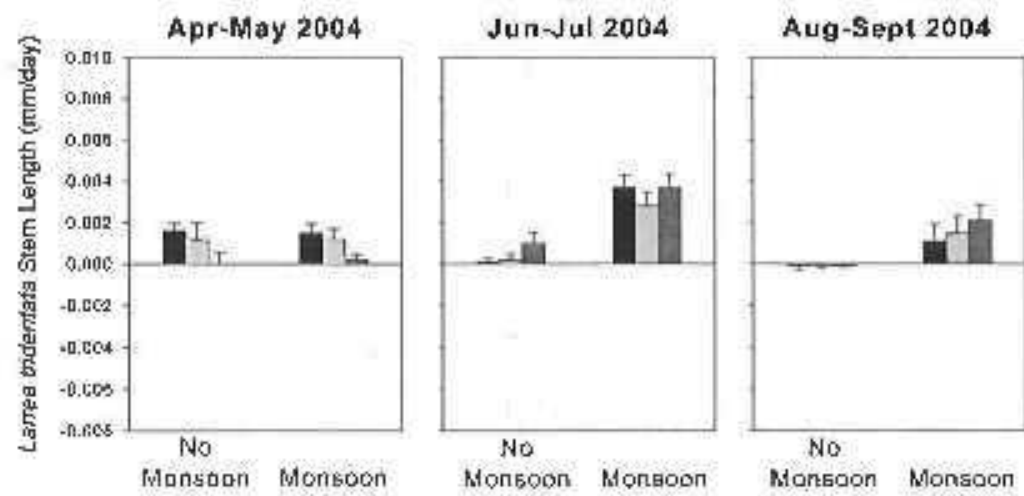

Apr-Stet 2004
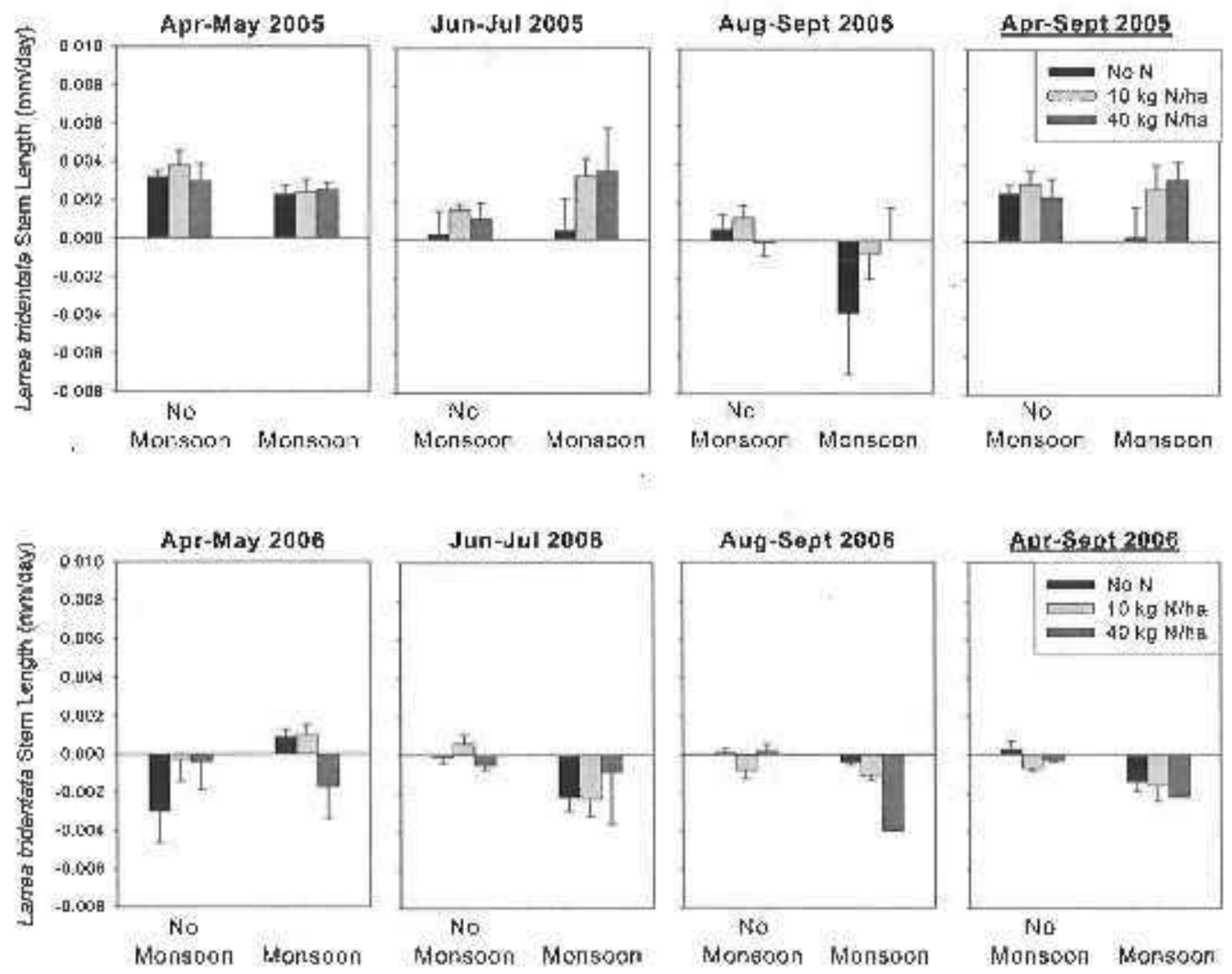

Fig. 2 Relative growtls rate of Larrea tridentata in response to simulated summer monsoons and nitrogen addition ( $\left.\mathrm{CaNO}_{3}\right)$. Measurements were taken on $50 \mathrm{~mm}$ growing lips, which were marked each spring. Enor bars represent \pm 1 standard error. 

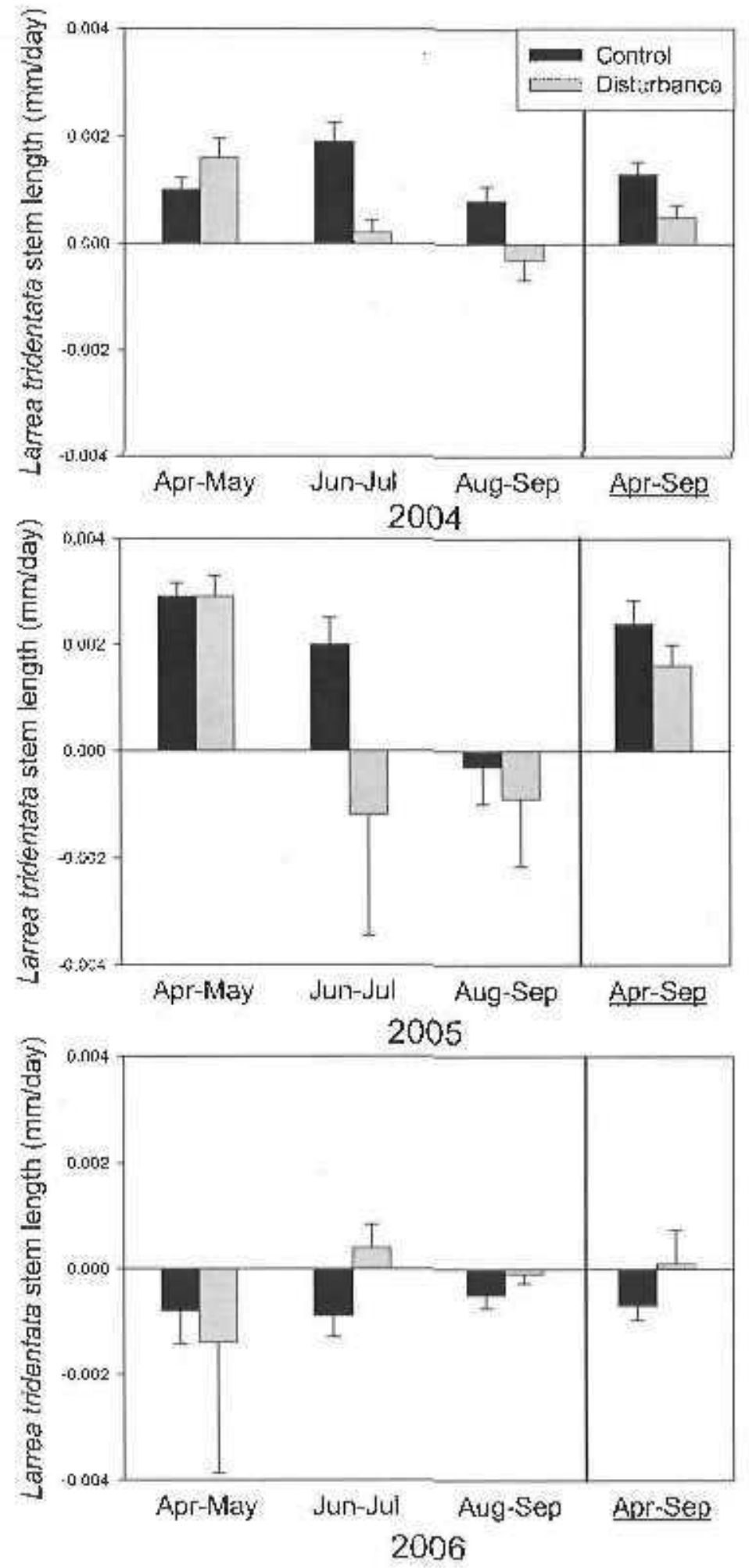

Fig. 3 Relative growth rate of Larea tridentato in response to soil disturbance. Measurements were hiken on $50 \mathrm{~mm}$ growing tips, which were marked each spring. Eisor bars represent +1 standard etror. 


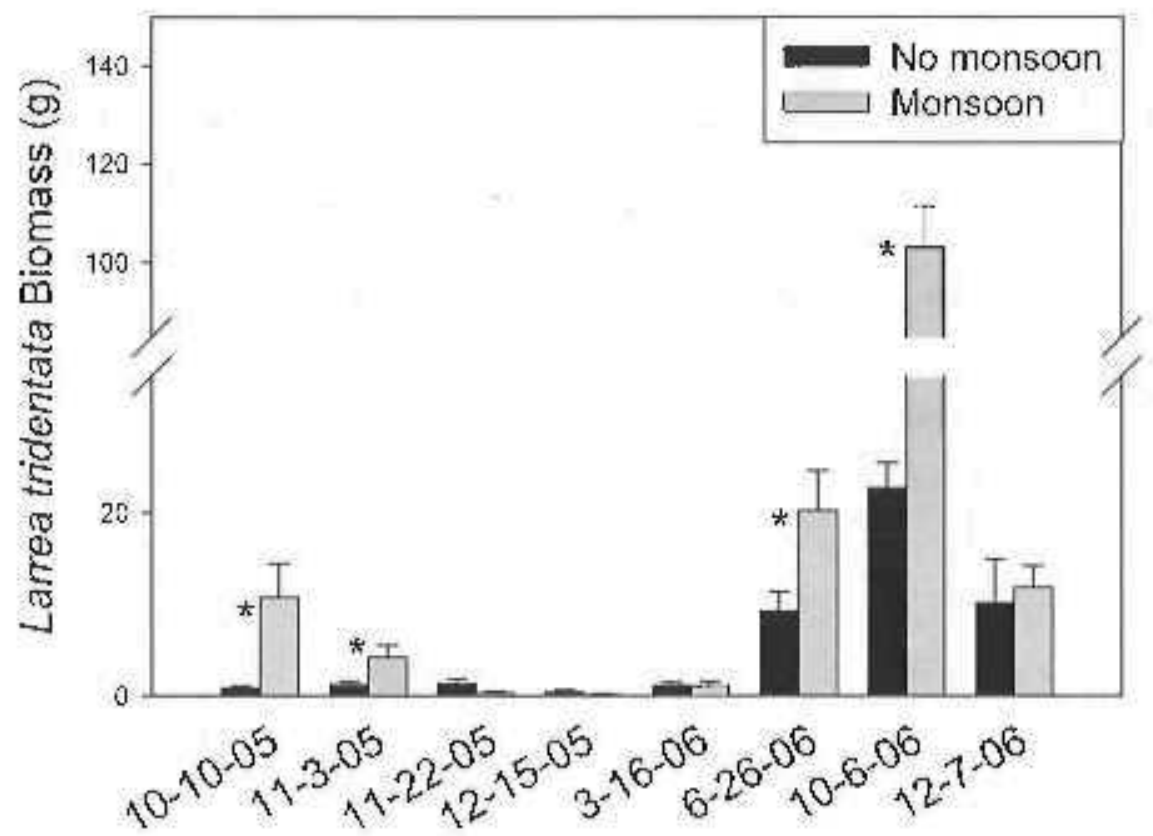

Fig 4 Larrea tridentata biomass removed by rabbit herbivory in response to simulited suminer monsuons. Nitrogen addition had no eflect on the amount of biomass removed; therefore, means includo no nitrogen, $10 \mathrm{~N}$, and $40 \mathrm{~N}$ treatments. Errot bars represent \pm 1 standard error. Asterisks represent $\mathrm{P}<0.05$.

\section{WATER BALANCE [R.Nowak, PI]}

Soil water measurements [C.D.Holmes, K. Allcock]

Soil water content anong different plots was monitored by measuring volumetric soil water content with a neutron probe (Model 503 Hydroprobe, Campbell Pacific Nuclear Corporation, Martinez, CA, USA). To characterize deep soil moisture, a 2-meter deep neutron probe access tube was installed in a plant interspace near the center of cach of the $96 \mathrm{MGCF}$ plots. Neutron probe measurements began in March 2001 and have continued until present time; data from March 2001 to June 2006 are included in this report. Neutron probe measurements typically are taken at 4 -week intervals, except during summer irrigation treatmonts and following specific rainfall events, when measurements occur at shorter intervals to better characterize the rate of water gain and loss. Measurements were made at $0.20 \mathrm{~m}$ soil deptlt and then at $0.2 \mathrm{~m}$ depth increments to a soil depth of $1.80 \mathrm{~m}$. To facilitate the comparison of soil water data for different increments of soil depth, we converted the neutron probe measurements of soil water from volumetric percent soil water to an equivalent depth of water (mun). We followed the procedures in Anderson et al. (1987) to detemine the total amount of water in the soil profile from the sufface to a depth of $1.90 \mathrm{~m}$ (i.e., half the $0.2 \mathrm{~m}$ depth increment past the $1.80 \mathrm{~m}$ depth reading) (Nowak et al. 2004). 


\section{Stalistical analyses}

We used two approaches to compare and analyze the experimental data. The first approach was to use a longitudinal (time series) data analysis on the entire data set using a radial smoothing technique (SAS Froc Glimmix, type = rsmooth) to model the eovatriance for each plot through time (SAS 9.1, (1) SAS Institute 2002). In order to maximize the predictive power of the radial smoothing model, we included the amount of precipitation, time (days) since irrigation, and all treatment interactions. The secend approach we used was to divide the data set into time periods focusing on the sampling dates during the summer irrigation treatments as one time period (July - August) and the sampling dates between the irrigations as another time period (September - June), By splitting the data set in this manner, we were able use an equally spaced autoregressive repeated measures ANOVA (SAS Proc Glimmix, type $=$ ar 1) to analyze the data.

For the detailed analyses of soil moistute responscs during the irrigation months (July-August), we omitted the non-irrigated plots. In the absence of precipitation, soil moisture was extremely low in non-irrigated plots, and the variance was proportionally low, resulting in very unequal variances between irrigated and non-irrigated plots (thus preventing convergence of the statistical model). Nitrogen addition treatment, irrigation number (first, second or third), crust dislurbance, and precipitation were the fixed effects. Random effects were block and plot. The detailed analysis of the months betwecn the irrigations (September - June) were done in a similar fashion except that the non-irrigated plots were included. Mean comparisons for significant factors in the ANOVAs were made with the "Ismeans/diff" command in SAS. Because the large sample size and many sampling dates lead to high denominator degrecs of freedom for $F$ tests, $P<0.01$ was considered significant. In all eases, we modeled the data using a lognormal error distribution in l'roc Glimmix (this is equivalent to performing a log transformation on raw dala and sumning a Gaussian or normal model). For all analyses our random effects were blocks and plots, and we used the Random residual option of Proc Glimmix to model the covariance structure (either a spline fit for the radial smoother or an autoregressive model for the repeated measures analyses).

\section{Results}

Radial smoothing model

There were no significant interactions between any of the nitrogen or crust treatments for total soil water content (TSWC) or at any of the individual depths. For I'SWC and for water content at each depth, the continuous variables of days since irrigation (DSI), days, precipitation, and the interaction of these three tems were nearly always significant. For TSWC, the only additional interaction that was significant was precipitation $\times$ DSI $x$ irrigation. The 20 and $40 \mathrm{~cm}$ depths showed identical results and are the only depths where an irigation effect was significant (Fig. 5). All of the depths from 60 to $180 \mathrm{~cm}$ responded similarly with the only significant factors being the contininous yariables mentioned above and the interaction of those variables. The only exception to this was a significant interaction of DSI $x$ days $\times \mathrm{N}$ at the $180 \mathrm{~cm}$ depth.

\section{Irrigation months (July - August)}

It is important to remember that for this analysis only the irrigated plots were used. There were no significant interactions between any of the nitrogen treatments for tolal soil water contcnt (TSWC) or at any of the individual depths. For TSWC and the 20,40 , and $60 \mathrm{~cm}$ depths, irrigation number $(1,2$, or 3) (Fig.6) and crust (Fig.7) were significant. The only other significant factor in this analysis was the interaction of precipitation $\mathrm{x}$ irrigation for ISWC and for the $20 \mathrm{~cm}$ depth. 
Between irrigation months (September - lune)

For TSWC and all other depths, the factor of month and the interaction of month $\mathrm{x}$ precipitation were all significant. For TSWC, there was a significant irrigation effect, irrigation $\mathrm{x}$ month effect, and a nitrogen effect. The 20 and $40 \mathrm{~cm}$ depths showed similar results with irrigation $x$ month and precipitation $\mathrm{x}$ irrigation being significant. However, there was a significant irrigation effect at $40 \mathrm{~cm}$ and not at $20 \mathrm{~cm}$. The 60 to $120 \mathrm{~cm}$ depths all showed similar results in that there was significant nitrogen $x$ crust and irrigation $x$ nitrogen $x$ crust interactions. At 60 and $80 \mathrm{~cm}$, there was a significant irrigation $x$ month effect, and at 60 and $120 \mathrm{~cm}$, there was a significant irrigation eflect. The 140 to $180 \mathrm{~cm}$ depths were very similar in that the irrigation effect continued to be significant. There was also a nitrogen effect at 160 and $180 \mathrm{~cm}$.

Some other highlights of our findings that do not particularly relate $w$ any onc of our analyses are that an additive effect occurs with subsequent irrigations, which drives the water deeper into the soil profile with each 25 mm isrigation event (wetting front increased from about $401060 \mathrm{to} 80 \mathrm{~cm}$ from the first to third irrigation) (Fig.8). Also, by the end of the 3rd irrigation (mid-August) irrigated plots had about 3.5 times more soil water content (\%) than non-irrigated plots in the top 1 meter of soil (Fig.8). Another interesting finding has been the response of all plots to a large pulse rain event that vecurred in December 2004. In December 2004 we received approximately $29 \mathrm{~mm}$ of rain in one event The wetting front from this large pulse event took approximately five months to reach $180 \mathrm{~cm}$ (the deepest measurement we lake) (Fig. 5).

Our initial hypothesis was that plots that were irrigatled, had intact biological soil crusts, and no nitrogen additions would have higher overall soil moisture content. We must rejcet our overall hypothesis and conclude that the combination of irrigation, intact soil crusts, and no nitrogen additions does not lead to higher soil moisture. Obviously, there were times throughout the year when irrigated plots had higher soil moisture than non-irrigated plots as well as plots with crust were wetter than plots with disturbed crust. There were also occasions when there was a significant nitrogen effect, but the effect was never consistent in that plots with nitrogen addition were at times wetter and at times dryer. There was never a time when all plots representing all three of the treatment factors had higher soil moisture than the other plots at the same time of year.

\section{Discussion \\ Radial smoothing model}

The radial smoothing model showed that there is a correlation between the irrigation treatment and the amount of precipitation that is received in a given year. This is an important linding because it helps explain why in some years the irrigation elfeet lasts longer into the following year than in other years. The radial smoothing model also showed a signifieant interaction of DSI $\mathrm{x}$ irrigation for ISWC and at the 20,40 , and $60 \mathrm{~cm}$ depths. This result suggests that there is significantly more soil moisturc to a depth of $60 \mathrm{~cm}$ as a result of the irrigations (Fig.8), but that the effect is dependant on the amount of time since the last irrigation, which is what we would expect to see. The radial smoothing model, being a prediclive model and not a mean comparison model, was helpful to us by atlowing us to use the entire data set and identifying overall trends in the data as well as the DSI inleractions.

\section{Irrigation months (July - August)}

By partitioning the irrigations from the rest of the data set we were able to examine the additive effect of each irrigation. Both Fig. 6 and Fig. 8 show the additive effect of each subseguent irrigation with TSWC being the most dramatic change in soil moisture. From the first to the third irrigation, irrigated plots gained approximately 13 additional $\mathrm{mm}$. Thirteen $\mathrm{mm}$ may sound low considering that 